New Zealand journal of industrial relations. 1986, 11. 177-189

\title{
Occupational health and safety legislation: possibilities for future development
}

\author{
Ian B Campbell*
}

That there should be much greater attention to the problem of occupational health and safety may be demonstrated by the out-dated and fragmented legislation and its administration now current in New Zealand, notwithstanding recent legislative changes. It is suggested that there are many factors that should be considered in developing a new course of action and recent approaches in some other countries, notably Britain and Canada, are examined for their relevance to New Zealand's future needs. Among the factors considered are scientific, economic, ethical and political aspects. Probably the greatest need lies in the necessity of paying a lot more attention to the health effects of the working environment. Also recommended is a well-informed approach to self-regulation which involves all in the workplace and, as a consequence, calls for a lot more training and education. Joint training for all members of management-labour committees is regarded as essential. A tripartite authority is proposed to take over the present role of government departments.

\section{Introduction}

Unlike many other countries with which New Zealand has the closest ties such as Australia, Canada, Great Britain and even the United States, New Zealand has refrained from making significant changes in occupational health and safety legislation in recent years. This, despite the opportunities afforded by the passage in 1981 of the Factories and Commercial Premises Act and the Tunnels and Quarries Act in 1982.

Unfortunately it still needs to be emphasised that the passing of such legislation is, in itself, but one step towards healthier and safer workplaces though nevertheless, a very important one. Thus a question which needs to be asked is whether there is an appreciation of the real need for and the true role of such legislation. Along with this approach there must be a recognition of the fact that legislation, no matter how well drafted, conscientiously complied with and enforced, cannot be effective in many of the areas that need attention. There is the often unrecognised but vital fact that it provides only the base line, the minimum standard that should be attained. This is a point that recently caused an oil company spokesman to comment that: activities such as oil refineries and installations are only as safe as they are, because oil companies take far more precautions than the law requires.

It is logical, when considering the direction and extent of the path that any future legislation should take, that attention be given to a wide range of factors, such as scientific, economic, ethical and political considerations. Whilst scientific and economic approaches may help assess the extent of the risk, probabilities of harm and costs of preventive measures, the determination of the acceptability of the residual risk is entirely a political issue, decided hopefully with due regard to ethical aspects. As political decisions are so often made in an atmosphere clouded by emotive approaches and are subject to pressure group activity, it is important that those decisions be made on the basis of the best available evidence in a forum wide open to public scrutiny.

In recent years there has been a great deal of adverse comment on our fragmented safety legislation and its administration spread through a number of government departments. This is in marked contrast to developments elsewhere and such changes that have been made in New Zealand have been minimal. This leaves open the question of the part, if any, played by departments desirous of perpetuating their own particular bailiwicks.

* Teaching Fellow in Safety and Occupational Health Massey University. 


\section{Current trends overseas}

Simply put, the trend has been for a single all-embracing occupational health and safety statute replacing the earlier practice of having separate statutes for the major sectors of industry. In 1981, this approach was given a further impetus when, at the general conference of the International Labour Organisation (ILO) of that year, Convention 155 and Recommendation 164 concerning occupational health and safety and the working environment were adopted. There was a special significance in that step, for all previous conventions regarding health and safety concerned an individual industry or hazard. It is more than a little surprising that in the years that have passed since that Convention and Recommendation were agreed, they have raised scarcely a ripple in New Zealand, especially in the light of the considerable legislative activity in other countries. This is not an indication of the low priority placed on occupational health and safety but rather the lack of an adequate awareness. In 1985, carrying on its concern with these matters, the ILO adopted Convention 161 and Recommendation 171 concerning occupational health services.

What then are the major changes taking place? The accent is on communication, cooperation and education with considerable emphasis being placed on worker participation including:

a worker's right to know the hazards faced;

a worker's right to participate in the determination of health and safety measures;

a worker's right to refuse to undertake work where there is reasonable justification for so doing on the grounds of health and safety.

\section{A question of practical politics}

It has been accepted that much human activity is undertaken at some risk, either to the participants themselves, to others or both. However it has been equally accepted that in many cases the appropriate authority is entitled to require those involved so to modify or control their activities that the risk of harm is at least minimised if not completely eliminated. The major issue has always been deciding the extent to which the regulators should seek to interfere with the activities of individuals. On the one hand there are those who demand the maximum preventive activity on the part of the authorities and on the other, there are many who would stoutly resist such interference in what they firmly believe to be their sole prerogative. In the past such matters have usually been resolved as a question of practical politics; the outcome often depending on the political philosophy of the ruling party as well as the pressures and arguments that can be brought to bear by the interests concerned.

Many have looked to science to produce definitive answers to such problems as cause and effect but regrettably that approach often poses more questions than it provides answers. One has only to think of carcinogens in this regard. Epidemiological studies require both time and adequate data; neither of which is to be found in abundance. Thus quite frequently the confounding or inconclusive scientific evidence merely leads to a pragmatic response often based on political considerations alone.

What then are the influences which may determine the extent of the current regulatory efforts and, even more importantly, is the heed paid to such influences justified? Superficially it could be asserted that the ideologies of the ruling political forces will prevail, be they freemarketeers or interventionists. More frequently some middle course will emerge, though clearly there will be occasions when such an approach based on compromise cannot be justified. Another factor is that governments frequently rely on their departmental advisers. and the respective personalities, and relationships of ministers and their departmental heads may have a decisive influence on the course of events. The traditional caution often displayed by the latter can be a vital factor in the shaping of any action taken or avoided; though forward-looking and progressive attitudes often prevail.

Opposition by employer interests upon whom, at least initially, the cost of preventive measures will fall, is to be expected. However worker interests often complain that they see a tendency for the enforcement agency to be more attentive to employers' economic considerations than to workers' health and safety. As Mendeloff (1979, p.77) put it: "Another influence that reinforces union leaders' tough position on standards, at least in the health area, may be the company they keep. As many political scientists have observed, agencies and 
clientele groups can become symbiotic." Mendeloff goes on to point out that the reverse can also apply and the dilemma of the enforcement agency is to steer a reasonable course between the opposing views, and to be seen to be doing so.

\section{Ethical considerations}

In the search for indicators to which the legislators could look for guidance, ethical considerations must receive some consideration. Such considerations must also enter the relationship between management and labour. In a study for an Ontario Royal Commission, Tuohy and Trebilcock (1982) considered 2 perspectives: a utilitarian and a Kantian. They conclude:

A utilitarian perspective would, much like the economic framework, subject issues of safety and risk to a kind of social cost-benefit analysis. Are more social benefits derived from a given level of safety and risk than the social costs imposed on the risk bearers? A Kantian perspective would. on the other hand, stress the paramount ethical value placed on individual autonomy and the importance of not threatening that autonomy by subjecting individuals to risks to life and health that jeopardise their prospects of living out their lives in a dignified and fulfilling way. While all risks to life cannot be eliminated in any society, at least the burden of them should not be disproportionately distributed. A widely participatory and accessible set of institutional arrangements for determining socially acceptable levels of risks in particular settings seems suggested by the Kantian emphasis on equality in the burdens of risk bearing. (p. 10)

The latter view seems to be shared by Gewirth (1980) who, writing on human rights and the prevention of cancer, concludes:

So far as the moral responsibility of agents is concerned, the Right to the Non-Infliction of Cancer is an absolute human right, and it requires the most determined efforts both to ascertain when such affliction is likely to occur and to take all possible steps to prevent it, and thereby to make its respondents fulfil their correlative duties. (p.125)

\section{The economics of deterrence}

Much has been written by economists on the economics of preventive action and this can be summarised in Figure 1 which illustrates the desired objective of reaching a point where the combined total of expenditure on preventive action and the cost of accidents that are not prevented, is at the lowest possible level. However attractive that proposition may be in theory, in practice, it is of little value unless one is able reasonably to estimate the various factors involved. Whilst it is not difficult to accept that for a given expenditure $\mathrm{X}$ on prevention, there will be a decrease of $\mathrm{Y}$ in the number of accidents and illnesses: but to assess the respective values of $\mathrm{X}$ and $\mathrm{Y}$ and their relationship at various levels is quite another matter. Furthermore, is it reasonable to apply such an arbitrary cut-off point as the principle would suggest and if not, where should the line be drawn? The conflict between the cost of prevention and the benefit to the workforce of any proposed regulatory measures has been very evident in the United States even involving decisions of the Supreme Court of that country.

Whilst some would maintain that the cost of any proposed safety measure could be assessed reasonably accurately, few would care to be positive about assessing the benefits of any such measures particularly in dollar terms. Such pertinent aspects as the value of a life saved have been the subject of many learned papers but these present a wide diversity of opinion. Again, the information needed to estimate the cost of any measures is almost entirely in the hands of one party - the employers. That this should be a cause for concern is evidenced by the greatly exaggerated cost estimates that have been sometimes provided in the United States by industry representatives opposing more rigid controls, for example in the vinyl chloride industry; even though several PVC workers had died from contracting the rare cancer angiosarcoma.

In deciding which countermeasures to adopt, caution is necessary. Hasty action may result in the community at large being denied the benefit of a valuable product. There is also a limit to the costs that any industrial unit can afford. There is no point in having the safest workplace in the country, if products become so expensive that they can no longer be sold. Also 
Figure 1: Relationship between loss and prevention costs

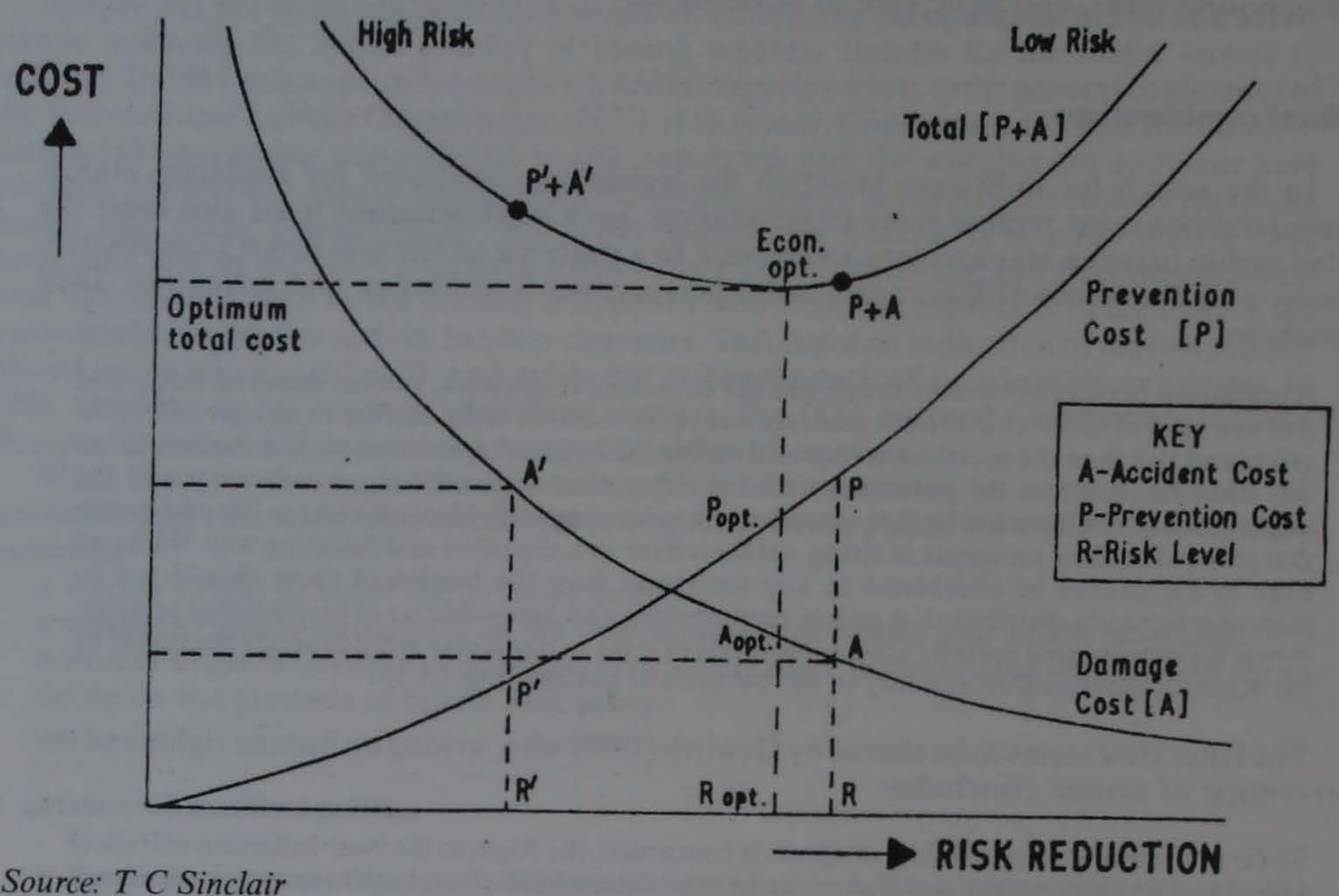

Figure 2: Principal relationship of cost-effectiveness of risk reduction considering the total economic system

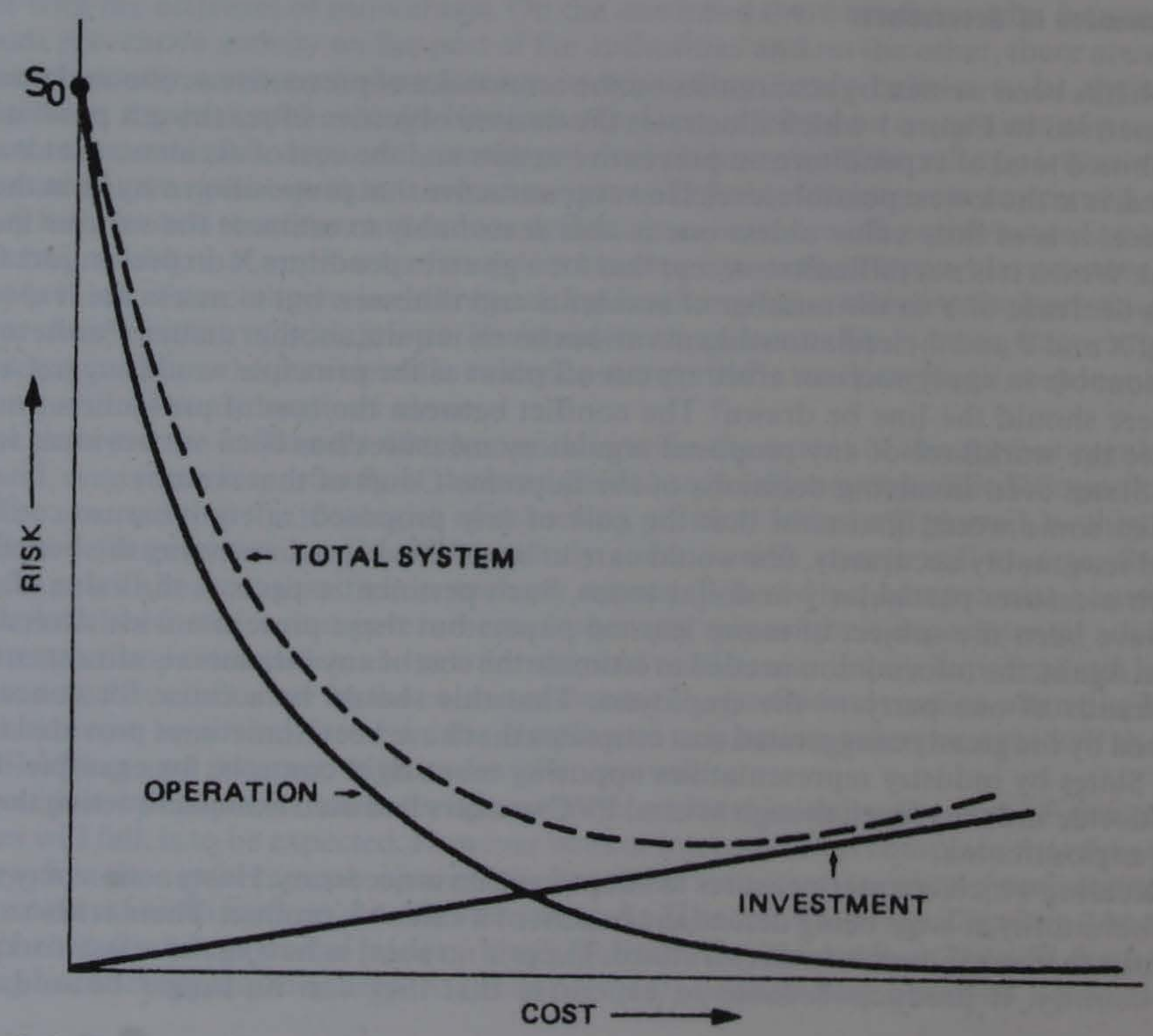

Source: S C Black and F Niehaus 
expenditure on safety in any one place may involve an increase in risk elsewhere.

Figure I demonstrates that, within an organisation, there will be a gradually increasing cost but a diminishing return for every dollar expended on health and safety. Figure 2 takes a different approach. It is concerned with the provision of safety equipment; its cost, including the manufacturing, transporting and installing of that equipment and also the risk to the public (for example, rollover protection for tractors cannot be produced without risk or without incurring its own safety expenditure). Research undertaken in the Federal Republic of Germany (Black and Niehaus, 1980) demonstrates how there will come a point when an increasing investment in safety equipment will result in an increase in the total cost to the community (injury and damage plus prevention expenditure). In this study not only were occupationally-related illnesses and injuries considered but also the effects on the whole community; such as pollution, accidents on the highway connected with the transport of safety equipment etc. At 1970 values. it was estimated that the expenditure of \$US33 000000 on safety equipment will result in an equivalent death during the construction, transport and installation of those safety measures.

\section{Alternativies to enforcement by regulation}

Considerable disenchantment with some aspects of the conventional regulatory approach has caused some researchers to give consideration to other possible methods. However, little interest has been aroused in New Zealand in some of these suggestions. One idea which has been advanced in the United States is that of an injury tax. Mendeloff $(1979, p .26)$ gives 3 reasons for suggesting that the enforcement of safety standards by regulation is less efficient than the suggested injury tax. He points out that a substantial number of injuries, for example strains and overexertion. would not be prevented even if all standards were complied with. Preoccupation with safety standards may divert resources from prevention of these nonstandards-related injuries. Even with those injuries for which compliance with standards is appropriate, changes in the physical environment required by standards may not be the most effective method. Education and training may be far more efficient. Finally Mendeloff points out that a particular standard may not be the least costly method of ensuring the desired level of safety.

Another factor advanced in favour of an injury tax is that the cost of accidents and illnesses is not all internalised to the employer's enterprise and thus the tax they would pay would, at least in part, equate to that social cost not bourne. Mendeloff (1979, p.27) comments:

Unlike the standards approach, an injury tax would give employers an added incentive to prevent all types of injuries and would not constrain them from employing the least costly preventive measures... an employer will usually have better information about the least costly methods for preventing injuries in his workplace than the Government does.

Though the advantages of such an approach have been pressed by economists, the injury tax proposition has received little support in the United States, even from employers who may be advantaged by such a system. The suggestion that the tax could be regarded as a "licence to maim" would clearly make it less attractive for most politicians, let alone unions and other interested parties. Undoubtedly it would be unlikely to find much support in New Zealand.

Some may consider the provision of the Accident Compensation Act 1982, that requires an employer to pay the compensation for the first 7 days of incapacity as being somewhat similar in effect to an injury tax. Atiyah (1975, p.103) even suggests that the period could be extended to 4 to 8 weeks without any right of recoupment from the insurance fund. An alternative approach is an experience rating system.

\section{Experience rating}

Experience rating, as developed in the workers' compensation field, can take several forms, but in essence involves an adjustment to an individual employer's premium based on the claims or accident record of that employer over the previous few years, as viewed against that of his particular industrial classification as a whole. A major drawback is that inevitably reliance has to be had to events in the past. This assumes that, other things being equal, the past performance of the organisation will continue unless there is some new influence or 
change. Another factor is the random nature of accident occurrences, for example, the bunching of events within a given time span may be no more significant than the absence of such events in that same time span.

There is the difficult question of whether adjustments should be on the basis of frequency alone or whether the cost of claims, or some other measurement of their severity, be taken into account. Chance frequently determines the extent of any injury, and it may be argued that this may not reflect the standard of the safety and systems management of the enterprise. Furthermore, experience rating is not applicable to the prevention of work-related illnesses. Many illnesses are contracted over a period of many years, and often in the service of more than one employer.

Despite the considerable support that such schemes enjoy from those who believe in their efficacy as a preventive measure, particularly in North America, there is a remarkable lack of empirical evidence to support this conclusion. There is some evidence from Ontario that the imposition of severe penalties ( 100 percent plus) can be effective. However the following comment from a report from the Economic Council of Canada (1981 p.278) suggests otherwise.

In summary, neither experience-rating nor penalty assessment as implemented in Ontario appear to represent effective devices for inducing employers to prevent accidents... On the other hand, the fragmentary evidence suggests that the imposition of penalty assessments is frequently unrelated to the most recent accident rate of the employer. Moreoever, the effectiveness of the assessment system is further reduced by the cancellation of penalties, the number of workers effected and the trivial nature of financial repercussions that are imposed on employers who have a "poor" accident record.

The present writer believes that there is a need for a supplementary approach to that of merely determining an employer's rating by means of some structured significance test; and suggests as a possibility, the type of safety audit developed by the International Loss Control Institute and which is now being used in many countries (Campbell 1980a, 1980b). In New Zealand it is being implemented by the Accident Compensation Corporation.

Though safety audits may be designed for any enterprise, irrespective of size, the sheer logistics of such an exercise, if applied to all concerns, would rule them out. Such schemes (significance testing and audits) are, in the main, only applicable to the larger undertakings. Though the efficacy of safety audits as a prospective preventive measure in the individual enterprise cannot be denied, in no way could they substitute for regulation and enforcement. any more than could incentive rating.

\section{The question of sanctions}

In many jurisdictions, like New Zealand, though provision is made for sanctions to be applied in the case of a failure to observe regulations, the actual imposition of sanctions is almost nil especially when these comprise criminal prosecutions. Furthermore it is normal for such sanctions to be minimal fines. The reluctance to prosecute, except as an avenue of last resort, stems largely from 2 reasons. Taking prosecutions is a time consuming process and most inspectors claim that education and persuasion are much more effective. They maintain that the objective is to ensure compliance and not to impose fines; and that time spent in the field is a much more efficient use of the limited manpower than if spent in the office laboriously preparing the documentation required for prosecution and subsequent attendance at court. With all but the smallest employers being corporate bodies, prosecutions tend to be inappropriate. With the largest corporations fines would have to be very heavy for them to have a real influence on company policy. Publicity about a prosecution may be more damaging to a reputation than a fine, but publicity cannot be guaranteed.

Others assail the reluctance to prosecute as a timorous approach which appears to signal that the regulations will not be rigorously enforced. They call for a much firmer hand. Their view is that only a policy of uncompromising enforcement will ensure adequate compliance. Some even advocate that in flagrant cases prosecutions be taken against individual members of the management team held culpable.

Santes (1985) in commenting on the Ontario scene referred to labour's view that unless inspectors were writing out compliance orders, they were not doing their job. Nevertheless in a 
report prepared for a Royal Commission concerned with asbestos. Doern et al. (1982, p.5.15) the following appears:

It is our view that in the long-run democratic context of regulation. prosecutions and penalties are the least likely way to secure sustained desired changes in behaviour if they are the primary force for change. In this sense the preference of the Ontario regulators to use persuasion and bargaining is both understandable and desirable. There can be no doubt. however, that the tendency of Ontario regulators.... to view prosecutions as an indicator of regulatory failure is overdone and is an important source of the view held by some groups particularly labour unions that the law is not being applied fairly. Visible prosecutions where they are clearly warranted can also reduce the need for more inspectors since people will change their behaviour in anticipation of such coercive consequences.

Clearly there is validity in both views but it would seem difficult, if not impossible, to reconcile the 2 views so long as the legislation provides for criminal penalties, even though prohibition and improvement notices can be a very useful tool. The question which must be addressed is, why should there not be an alternative approach? In the United States the Occupational Safety and Health Act 1970 (OSH Act) provides for civil penalties, which are simply implemented by an inspector's citation following an inspection. Again in British Columbia the Workers' Compensation Board has its own health and safety regulations and if there is a breach of those regulations or even if the workplace or working conditions are considered unsafe, the Board may assess and levy the employer a percentage of the premium paid to the Board for workers' compensation.

\section{Self-regulation}

A great deal of debate was sparked off in Britain following on from the Robens Report's (1972) criticism of: ".... too much reliance on state regulation. and rather less on voluntary selfgenerating effort." (p. 7). The report goes on to advocate a reduction in the sheer weight of the legislation. Earlier in the report. however, the committee stated that it was "in no doubt that the most important single reason for accidents at work is apathy" (p. 1). Understandably critics of the report seriously questioned the proposition of whether, given the extent of apathy, selfregulation could be effective. A closer reading of the report indicates that what was being recommended was not the substitution of self-regulation for regulation but a comprehensive statute setting out broad principles with the detail contained in supplementary regulations but, wherever possible the more practical codes of practice. The self-regulatory approach was intended to supplement the regulations. It was not just to be implemented by management as it saw fit. The intent was to involve the whole workforce. It envisaged the appointment of workers' health and safety representatives, joint management-labour committees and similar bodies.

Paradoxically, though there has been provision for workers safety inspectors in New Zealand mines for nearly 100 years, until the passing of the Factories and Commercial Premises Act 1981, such an approach had not been considered in other industries. Even now the provisions have still to be implemented.

Some of the most cogent arguments for self-regulation are to be found in the report of the Royal Commission on Health and Safety in Mines (1976) of Ontario (the Ham Report). Dr Ham criticises the then emphasis on unsafe acts and conditions maintaining that "... it falsely dichotomises and greatly over-simplifies the organic circumstances out of which accidents arise" (p. 119). Recognising the fact that all in the workplace are likely to err. he saw the need for clearly-defined work procedures and responsibilities to be laid down and monitored by an internal audit. He stated:

\footnotetext{
... any internal system of direct responsibility will be imperfect and requires audit. not because of any inherent defect in form but because it is a human organisation in which conditions of work and concern for the well-being of persons create grounds for tension. (p. 152)
}

and later:

External audit can keep the basic internal system alert and responsive, but it cannot substitute for basic internal integrity which rests on the knowledge. training. experience. 
and commitment of management, supervision, and the worker. All parties are under an obligation to seek to eliminate anomalous conditions, organizational, technical and human. No party can claim that the beam is always in the other's eye. (p.152)

Finally Dr Ham claimed:

Openness, contributive participation by workers, and thorough accountability can reestablish the self-regulatory character of the internal responsibility system (IRS) at the company level as the key to the control of risks at work in a technologically complex future. The regulatory and auditing functions of the Occupational Health and Safety Authority should be designed to keep the internal system at the company level alert and responsive and to deal bluntly with the true offender.

The Commission believes that the objective of a sound balance between self-regulation and legal compulsion based on the constructive co-operation of all parties cannot be achieved within current government policy and traditional industrial practices, it has formulated the recommendations to promote the change it considers necessary for the future well-being of the workers in mines and plants. (p.258)

The final 2 sentences, it is suggested, are very relevant to the present situation in New Zealand.

Despite the fact that the Ham Report was only concerned with the mining industry, it led to the passing of the Occupational Health and Safety Act 1978. A more recent Royal Commission concerned with the use of asbestos in Ontario emphasised the importance of this approach by headlining one section of its report: "The Ontario Setting: The Centrality of the Internal Responsibility System".

After mentioning the importance of the Ham Report as the catalyst in the creation of the new Act, and after referring to the key recommendations in that report, the asbestos Commission's report stated:

The major instrument for realising these goals would be the joint health and safety committee. These principles became the cornerstore of the Occupational Health and Safety Act and the foundation for the regulations made thereunder. (p.506)

and later:

The essence of the IRS is that all those involved in the operation and conduct of a workplace should accept responsibility for the quality of its health and safety. In order for the system to be effective, the complete line of command, from the board of directors through the chief executive, senior officers and managers, supervisors and workers must accept the commitment to foster and improve health and safety in the workplace. The IRS is embodied in the Act in a number of important ways, for example, in specifying the duties of employers. the responsibilities of workers for protecting themselves, and the joint duties of employers and workers in legally mandated health and safety committees. (p.510)

Training is the key to the success of any health and safety endeavour no matter how organised and, in this, Ontario is no different. The asbestos Commission, after referring to the need for training commented:

the premium that the IRS places on joint management-labour involvement in the health and safety of the workplace invites joint rather than separate training programmes. In this regard, current training efforts in Ontario strike us as lagging behind the basic philosophy of internal responsibility. (p.525)

In the general safety training programmes carried out by the Ontario safety associations and funded by the Workers' Compensation Board, there is no input by organised labour, which is not represented on the boards of the associations. This has resulted in the Ontario Federation of Labour setting up its own programmes. There has been a long-standing disputation by organised labour about the lack of representation and their view has been backed by more than one Royal Commission. Their concern has received added impetus with the recent emphasis on joint action and the IRS. One association, the Industrial Accident Prevention Association, has, however, developed a programme for the joint training of committees. 
Clearly, unless workers' representatives and all committee members are adequately informed not only of their duties but of all hazards in the workplace, its processes, materials and products, they cannot perform their function effectively. Such information must be theirs as of right as would be reports of accidents and dangerous occurrences. etc. All of this must be clearly defined in the regulations.

In Canada, it is not only Ontario where joint management-labour committees and worker involvement are mandated by law, for this applies in some form or another in all provinces. How successful has been this move? Understandably differing views prevail, however, in a recent article Sentes (1985) outlines the successes and failures. Referring to the various views held by labour, management and government, he comments:

Many aspects. they agree have had a positive effect on employee health and safety. All parties are unanimous that the "right to refuse" is an important provision that is working well. Other successful elements of the system include the standard-setting process. improved education and training programs. greater availability of data and information and better record-keeping.

But at least two fundamental issues - the role of the joint committees and the function of labour inspectors - divide labour from both management and government. And that division may point to a serious flaw within a system that was designed, above all, to protect the worker. (p.15)

What then are some of the deficiencies? Labour representatives repeatedly mention that committees have no decision-making power and that they are unable to get recommendations implemented. Whilst there can be arguments on the desirability and extent of any decisionmaking authority given to committees. clearly if a committee's recommendations are consistently ignored. that is a certain recipe for failure. To quote Sentes again:

One has to question how perceptions of effectiveness could differ so greatly. After all. if health and safety committees are doing what they are designed to do, wouldn't that be reflected in reduced accident, illness and fatality rates? (p.17)

Unfortunately because of changes in procedures, absolute comparisons are difficult. Though fatality rates show a marked decrease, national work injury and illness rates show no improvement in the past decade. After commenting on management's conviction that joint training is he answer. Sentes further comments:

The objective of joint training is to develop common perceptions of risk as well as mutually agreeable mechanisms and approaches for reducing that risk. The underlying assumption of this approach is that once common values are agreed upon by workers and management, committees will perform as planned, outside of the "adversarial atmosphere" which characterize collective bargaining. (p.18) and later: and later:

Once the committees are stripped of their present adversarial features, the arguments goes, management will be more likely to recognise their appropriate role is resolving workplace health and safety problems. (p.65)

Sentes concludes:

A certain amount of dissension is inevitable among three groups with differing needs and concerns. But fundamental conflicts over the main components of the occupational health and safety system can only mean that the intended beneficiaries - the workers - are not being properly served. Employers in both the private and public sectors might do well to ponder the advice of Allan Flanders. a British industrial relations expert, who believes that: "If employers want to retain power, they have to learn to share it". To do this, legislators would have to make changes to the various health and safety acts and regulations. Without such changes, organised labour may well turn toward the adversarial process of collective bargaining to achieve its health and safety objectives. (p.65)

In a less optimistic commentary on worker participation in the European Economic Community, Gevers (1983, p.425) states:

Even if all the arrangements on worker participation adopted over the last decade were put into practice, it remains to be seen whether a significant change in working conditions would occur. Still, even in a case where worker representatives cannot be proved to have 
brought about an improvement in occupational health and safety, participation is valuable, since it is desirable in itself for workers to have a say in an area where their vital interests are at stake...the more improvement of the working environment comes into conflict with a firm's short term economic interests, the more worker participation may be needed as a prerequisite for careful decision-making process in which all interests receive their due weight.

With the likelihood of the provisions of the Factories and Commercial Premises Act being activated in the near future, New Zealand could well benefit from a study of the Canadian experience. It would seem that, whilst in Canada union views are changing, many employers are more rigid in their adherence to traditional views. Above all else however, the clear message that comes from Canada is the need for a lot more education and training and in the case of management-labour committees, joint training is essential.

\section{The effectiveness of health and safety legislation}

A great deal of research has been undertaken into the effectiveness of such legislation especially in the United States, in the wake of the OSH Act of 1970. In any discussion on this matter 2 aspects emerge as being of vital importance. Firstly, that the effectiveness of enforcement itself, will depend substantially on the political and administrative climate in which it operates and the funds and other resources thus allocated. Where, as in the United States under the Reagan administration, there is a substantial move to deregulation, that must obviously have its effect as witnessed by the considerable concern being shown at present by that country's organised labour. Secondly, and of perhaps equal or even greater importance, are the inherent limitations of regulation. In the main, regulation is more appropriate to the static physical situation and not to activity within the workplace which is in a state of constant change. Another important aspect is that many hazardous situations are not amenable to regulation.

In a 1973 study undertaken in Britain of 658 accidents reported to the factory inspectorate, in only 18 percent did there appear to have been a breach of a regulation. In a companion study on construction sites (1967) a similar conclusion was reached. The latter study also concluded that additional regulations would not have helped as most of the accidents were associated with habits of work, general site tidiness and human error.

Similarly from the United States, Mendeloff (1984) reported:

California accident investigations for 1976 show that the violations of the Occupational Safety and Health Administration's safety standards were a contributing factor in 13 percent to 19 percent of the 645 deaths reported to the workers' compensation program during that year. However, a panel of safety engineers judged that about 50 percent of these violations could have been detected if an inspector had visited the day before the accident. These findings indicate that the potential gains from stronger enforcement of current standards are limited but not insignificant. The likelihood that a violation contributed to a serious accident varied considerably among accident types, industries, and size classes of plants. (p.353)

Another finding of the same study was that 12 of the most frequently cited violations were never cited in connection with accidents which left over the possibility that they did not cause hospitalisation.

An example of a successful regulation frequently cited as such, is the British Power Presses Regulations of 1965 . That these regulations resulted in a substantial drop in power press accidents could well be due to the fact that the regulations were highly specific and not only were they preceded by detailed studies but they were accompanied by the thorough training of operators and tool setters. A New Zealand example would be the rollover protection for tractors.

Whilst it is interesting to review studies about the effectiveness of safety legislation in other countries, the only conclusion that can be reached is that there is no generally accepted agreement as to the most effective approach, or even the results that can be achieved. Furthermore each country's legislation has developed against the background of that country's social, political and industrial climate and thus in detail at least, is not transferable. In an interesting study between Sweden and the United States, Kelman (1981) makes the following comment: 
Differences in the enforcement systems in the two countries influence both the inspectors and the tenor of their inspections. American inspections are designed more as formal searches for violations of regulations: Swedish inspections are designed as informal personal missions to give advice and information, establish friendship ties between inspector and inspected, and promote local labor-management co-operation. (p.203)

Despite the generally accepted differences between "socialist" Sweden and "capitalist" United States. Kelman does not come to any firm conclusions about the effectiveness of the respective systems.

Finally, Ellis (1975) in his review of research efforts on safety promotion concludes:

No sound scientific evidence appears to exist with regard to the effectiveness of inspections for violations of government safety standards. The best data. which are still quite weak. concern the degree of potential influence, and these suggest that only if all violations of safety standards likely to be identified by inspections at this time were stopped. only one fourth of all occupational injuries would be stopped. (p.187)

Thus the evidence remains somewhat cloudy: whilst such legislation must have some effect but just how much is wide open to question. All of which clearly signals the need for a much more searching investigation into any proposed measures before they are adopted: to say nothing of the need for a thorough reappraisal of the current regulatory efforts.

\section{The influence of the trade union movement}

In the next few years it is likely that organised labour will make a determined effort to see greater progress: in fact it has already begun. As Gunningham (1984, p.368) in commenting on the current Australian scene states:

Given the conflict between rigorous safety legislation and employer self-interest. the power of the industrial lobby. and the reluctance of governments to take action ... radical reform is inconceivable in the absence of forceful and sustained pressure from the trade union movement.

He goes on to warn that the mere enactment of new legislation is not enough. The political will to enforce it and the vigilance of the trade unions would be vital. He envisages:

... occupational health and safety legislation .... entering a new phase, characterised by greater state intervention. more vigorous enforcement, and more direct and effective worker participation in conjunction with the provision of statutory workers' rights. (p.372)

\section{New Zealand's needs}

Perhaps it is first of all desirable to consider why many view moves toward greater worker involvement with considerable apprehension if not cynicism. Despite the considerable progress that has been made in the last 3 or 4 decades, many old attitudes still linger; the carelessness of workers, accident proneness, etc are still frequently cited. However as Kletz (1985) pertinently comments:

Well-trained, well-motivated men. physically and mentally suited to the job they are doing. and properly instructed. make occasional mistakes whilst carrying out jobs that they have often done before. We should either accept an occasional mistake ... or change the work situation. Telling people to be more careful or punishing them will not prevent mistakes... (p.11)

Again. as has already been mentioned. accidents seldom happen as the result of 1 cause.

In the past joint committees have been set up in New Zealand with no or inadequate terms of reference and training for such committees has been conspicuous by its absence. Again an argument frequently advanced by management is. that management must manage and that authority cannot be delegated to committees or members of the workforce. Robens, however. 
stresses that the promotion of safety and health is first and foremost a matter of efficient management and that:

... it is not a management prerogative ... real progress is not possible without the full cooperation and commitment of all employees. (p.18)

The efficacy of worker participation needs to be considered in the light of 2 other developments previously mentioned namely; a worker's right to know the hazards faced and also the right to refuse to undertake work where there is reasonable justification for that course of action. The first point is most important. For example the requirement in s 22 of the Factories and Commercial Premises Act requires that a dangerous substance be "clearly labelled". But that is quite inadequate especially in the light of the considerable attention that has been given to that subject in recent years and the problems that have arisen through insufficiently informative labels. That is but a small example of the changes that are needed. Other more wide-ranging changes would be those along the lines of the Canadian and other recent legislation in Britain, Australia and elsewhere as has been outlined.

It is essential that a lot more attention be paid to the health effects of the work environment. The growing complexity of modern industry could well bring with it health problems not yet envisaged, whilst even today many experts consider that there are many more work-related illnesses than is currently known or acknowledged.

\section{A National Health and Safety Commission}

The time for New Zealand to consider and implement far-reaching changes is certainly more than overdue. Merely to consider a single comprehensive statute and one enforcement agency would be but toying with the problem. What is needed is a much more innovative approach - a National Health and Safety Commission. The Commission as envisaged would be a tripartite body taking over the occupational health and safety role of the government departments and possibly, the educational role of the Accident Compensation Corporation (ACC).

On the governing body would be representatives of government, management and labour with an independent chairman who would probably be the only full time member of the Commission. No doubt, at least initially, its activities may be limited to the occupational field but, just as ACC has responsibilities in all safety education fields, there is every reason for the new Commission to have the widest possible terms of reference.

\section{Conclusions}

Satisfactory progress will depend on a determination to shrug off old attitudes and for these to give way to a realisation that, in recent years, there have been wide-ranging changes in the regulatory approach in many countries and these have been coupled with radically new promotional and educational activities. Important in these changes has been a realisation that much more attention has to be paid to the health effects of the working environment and its processes.

The time when we can afford a plethora of statutes and enforcement agencies is long gone. We would be well advised to study the Canadian legislation very closely especially that of British Columbia, Ontario and Quebec. The recent developments in Australia also deserve our close attention.

When the vital interests of capital and labour are considered, the setting up of a National Commission as suggested above which combined with effective self-regulation and worker involvement, all promise a future for occupational health and safety of great potential.

Without doubt, new legislation and a national authority must be matched by other changes. Foremost among these would be education, and whilst this paper has stressed the importance of an informed workforce, in truth, the need is across the board from the chief executive down. Only with this will the desired results be achieved. It seems too that if enforcement is to be pushed vigorously, then some alternative to current methods of prosecution is needed, perhaps similar to that of British Columbia. For many years, ever since the Robens Report was issued back in 1972, there have been calls for action. Why, one must ask, has there been so little? The time for action is now! 


\section{References}

Atiyah. P S (1975) Accident prevention and variable premium rates for work-connected accidents Industrial law journal 4:1-11.89-105.

Accidents in factories (1973) London. HMSO.

Accidents in the construction industry (1967) London. HMSO.

Black. S C and Niehaus, F (1980) How safe is "too" safe? IAEA Bulletin 22, 1, 40-50.

Campbell. I B (1980a) Accident statistics and significance: their practical application in New Zealand Palmerston North. Faculty of Business. Massey University.

Campbell, I B (1980b) Accident prevention activity: its needs and its measurement Control 6: $131-146$.

Convention 155 (1981) Geneva, ILO.

Convention 161 (1985) Geneva, ILO.

Doern, G B. Prince. M and McNaughton. G (1982) Living with contradications: Health and safety regulation and implementation in Ontario Toronto. Royal Commission on Matters of Health and Safety Arising from the Use of Asbestos in Ontario.

Ellis. L (1975) A review of research efforts to promote occupational safety Journal of safety research 7: 180-9.

Gevers. J K M (1983) Worker participation in health and safety in the EEC International labour review 143: 112-125.

Gewirth. A (1980) Human rights and the prevention of cancer American philosophical quarterly 17: $112-115$.

Gunningham, N (1984) Safeguarding the worker Sydney, Law Book Co.

Kletz. T A (1985) Human failing Hazard prevention 21: 5.11.

Kelman. S (1981) Regulating America, regulating Sweden Cambridge. Mass.. MIT Press.

Mendeloff. J (1979) Regulating safety Cambridge. Mass., MIT Press.

Mendeloff. J (1984) The role of OSHA violations in serious workplace accidents Journal of occupational medicine 25: 303-314.

Occupational health and safety: issues and alternatives (1981) Technical Report No. 6 Ottawa, Economic Council of Canada.

Recommendation 164 (1981) Geneva. ILO.

Recommendation 171 (1985) Geneva, ILO.

Report of the Royal Commission on health and safety of workers in mines (1976) Toronto, Government of Ontario.

Report of the Royal Commission on matters of health and safety arising from the use of asbestos in Ontario (1984) Toronto. Ministry of the Attorney General.

Robens report (1972) Safety and health at work: report of the committee Cmnd. 5034 London. HMSO.

Sentes. R (1985) Balancing the act Occupational health \& safety Canada 1: 15-18, 65.

Sinclair. T C (1972) A cost effective approach to industrial safety London. HMSO.

Tuohy. C J and Trebilcock. M J (1982) Policy options in the regulation of asbestos related health hazards Toronto. Royal Commission on matters of health and safety arising from the use of asbestos in Ontario. 